www.jmscr.igmpublication.org

Impact Factor 5.84

Index Copernicus Value: 83.27

ISSN (e)-2347-176x ISSN (p) 2455-0450

crossref DOI: _https://dx.doi.org/10.18535/jmscr/v5i4.184

Journal Of Medical Science And Clinical Research

\title{
A Relevance Study of Bone Marrow Aspiration and Bone Marrow Biopsy in Haematological and Non Haematological Disorders
}

\author{
Authors \\ Dr Daleep Kumar Khatik, Dr Deepika Mishra, Dr Mangilal Choudhary \\ Department of Pathology, SMS Medical College Jaipur, Rajasthan
}

\begin{abstract}
Introduction: Bone marrow examination is an important diagnostic tool for evaluation of various haematological and non haematological disorders. The two most important techniques used for the diagnosis are bone marrow aspiration and bone marrow trephine biopsy which are complementary to each other.

Aims and Objective: To correlate the bone marrow aspiration and bone marrow biopsy finding in haematological and non haematological disorders.

Material and Methods: A total of 150 cases with both bone marrow aspiration and biopsy were included in the study. All the aspirate smears were routinely stained by leishman stain while the trephine biopsy sections were stained by routine Hematoxylin and Eosin stain. All the smears and sections were examined and the findings of BMA and BMB compared to each other.

Results: In the present study out of 150 cases the positive correlation between bone marrow aspirate and trephine biopsy sections was $89.33 \%$ and sensitivity of bone marrow aspiration cytology was $83 \%$.

Conclusion: The study concludes that preparations of aspirate are easy as compare to trephine biopsy. However both these procedure are complementary to each other in majority of the cases. The advantage of both the procedures done together provide us to study the cytomorphology of the cells along with the pattern of distribution of the cells depending on the cases, hence help in making the diagnosis accurately.
\end{abstract}

\section{INTRODUCTION}

Bone marrow examination is useful in the diagnosis of haematological and nonhaematological disorders. Examination of bone marrow is one of the diagnostic cornerstones of haematological practice. It may also play an important role in the assessment of patient with pyrexia of unknown origin (PUO) as well as in the diagnosis of various storage and infiltrative disorders. ${ }^{(5)}$ Bone marrow examination usually involves two separate but interrelated specimen i.e. bone marrow aspiration and needle biopsy of bone and associated marrow. ${ }^{(18)}$
Bone marrow aspirate smears are generally important for evaluating individual cell detail. However because the process of aspiration disrupts cell cohesion, the relationship of various cell types and the marrow cellularity cannot be reliably assessed. An adequate bone marrow core biopsy adds this important information. Bone marrow biopsy is essential in case of 'dry tap' or 'blood tap' ${ }^{\text {(9) }}$ Hence, we attempted to correlate both these parameters to arrive at a more conclusive final diagnosis. 


\section{JMSCR Vol||05||Issue||04||Page 20900-20908||April}

\section{MATERIAL AND METHODS}

The study has been conducted for bone marrow examination on 150 cases. The patients had male to female sex ratio was $2: 1$ and a wide range of age from 3 years to 78 years. It includes patients who were admitted in SMS and attached hospital Jaipur (Raj.) between March 2015 to Nov. 2016, who were suspected to having their bone marrow involvement by any haematological or nonhaematological disorders. The relevant history and bio-data of patients were recorded and informed consent was taken. Patients were investigated for complete blood count, coagulation profile, chest $\mathrm{x}$-ray and USG abdomen also done for selected patients. Peripheral blood film (PBF) examination, BMA and BMB were done simultaneously for these patients. BMA was performed by Salah's marrow puncture needle; smears prepared were stained with leishman stain. BMB was done by Jamshidi biopsy needle and specimens were fixed in $10 \%$ formalin fixative and decalcified in EDTA for overnight and processed with paraffinwax embedding. Thin sections (3-4micron) were cut and were stained by Haematoxylin and Eosin (H\&E) stain. Special stain also apply whenever indicated. The staining for reticulin fibers with
Reticulin stain impregnation method was done in selected cases and grading was done. Bone marrow aspiration and Biopsy findings were analysed in context of clinical signs, symptoms and other laboratory investigations of the patients and try to reach at final diagnosis.

\section{RESULTS}

In the index study a total of 150 cases were subjected to bone marrow aspiration and biopsy in hematological and non hematological disorders. In our study maximum number of cases diagnosed as anaemia $(32,21.33 \%)$. In which megaloblastic anaemia was the commonest $(23,15.3 \%)$. The number of cases $(19 ; 12.66 \%)$ were diagnosed as acute leukemia, in which male to female ratio in AML was 4:1 and in ALL all three patient were male. Bone marrow aspirate was diagnostic and biopsy provided additional information in cases of megaloblastic anemia, CML, CLL, Plasma cell disorders. Bone marrow aspiration was 'dry tap' in $4(2.66 \%)$ cases, where bone marrow biopsy provided the diagnosis. The positive correlation between bone marrow aspirate and trephine biopsy sections was $89.33 \%$ and sensitivity of bone marrow aspiration cytology was $83 \%$.

Table 1. - Showing Distribution of Various disorders $(n=150)$

\begin{tabular}{|l|c|c|}
\hline Diagnosis & Number of Cases & Percentage (\%) \\
\hline Anaemias & 32 & 21.33 \\
\hline Acute Leukemias & 19 & 12.67 \\
\hline Lymphoproliferative disorders (LPD) & 17 & 11.46 \\
\hline Chronic Myeloproliferative Disorders (CMPD) & 18 & 12 \\
\hline Multiple Myeloma (MM) & 06 & 04 \\
\hline Myelodysplastic syndrome (MDS) & 04 & 2.66 \\
\hline Idiopathic Thrombocytopenic Purpura (ITP) & 02 & 1.33 \\
\hline Haemophagocytic Syndrome (HS) & 01 & 0.7 \\
\hline Hypereosinophilic Syndrome (HES) & 01 & 0.7 \\
\hline Eosinophilia (E) & 01 & 0.7 \\
\hline Metastatic Lesion (M) & 02 & 1.33 \\
\hline Granulomatous Lesion (GL) & 03 & 02 \\
\hline Normal Study (N) & 44 & 29.34 \\
\hline Total & 150 & 100 \\
\hline
\end{tabular}




\section{JMSCR Vol||05||Issue||04||Page 20900-20908||April}

Table 2. - Showing comparative evaluation of bone marrow aspiration and bone marrow biopsy diagnosis $(\mathrm{n}=150)$

\begin{tabular}{|c|c|c|c|}
\hline Distribution of Cases & $\begin{array}{l}\text { Bone marrow } \\
\text { Aspiration }\end{array}$ & $\begin{array}{c}\text { Bone Marrow } \\
\text { Biopsy }\end{array}$ & $\begin{array}{c}\text { Accuracy of Bone marrow } \\
\text { aspiration in } \%\end{array}$ \\
\hline Aplastic Anaemia & - & 2 & - \\
\hline ALL & 3 & 3 & 100 \\
\hline AML & 15 & 16 & 94 \\
\hline CLL & 9 & 11 & 81.81 \\
\hline CML & 14 & 16 & 87.08 \\
\hline Dimorphic Anaemia & 1 & 1 & 100 \\
\hline Eosinophilia & 1 & 1 & 100 \\
\hline Erythroid hyperplasia & 1 & 1 & 100 \\
\hline Granulomatous Lesion & 0 & 3 & - \\
\hline Hypoplastic Anaemia & 3 & 4 & 75 \\
\hline Hypereosinophilic Syndrome & 1 & 1 & 100 \\
\hline Hodgkin's Lymphoma & 2 & 3 & 66.6 \\
\hline Hemophagocytic Syndrome & 0 & 1 & - \\
\hline ITP & 2 & 2 & 100 \\
\hline Metastatic & 1 & 2 & 50 \\
\hline Megaloblastic Anaemia & 23 & 23 & 100 \\
\hline MDS & 4 & 4 & 100 \\
\hline Multiple Myeloma & 5 & 6 & 83.08 \\
\hline Normal & 46 & 44 & - \\
\hline NormalErythroid Hyperplasia & 1 & 1 & 100 \\
\hline NHL & 2 & 3 & 66.6 \\
\hline Primary Myelofibrosis & 0 & 1 & - \\
\hline Secondary Myelofibrosis & 0 & 1 & - \\
\hline Total & 134 & 150 & 89.33 \\
\hline
\end{tabular}

Positive correlation between bone marrow aspiration and bone marrow biopsy study was $89.33 \%$.

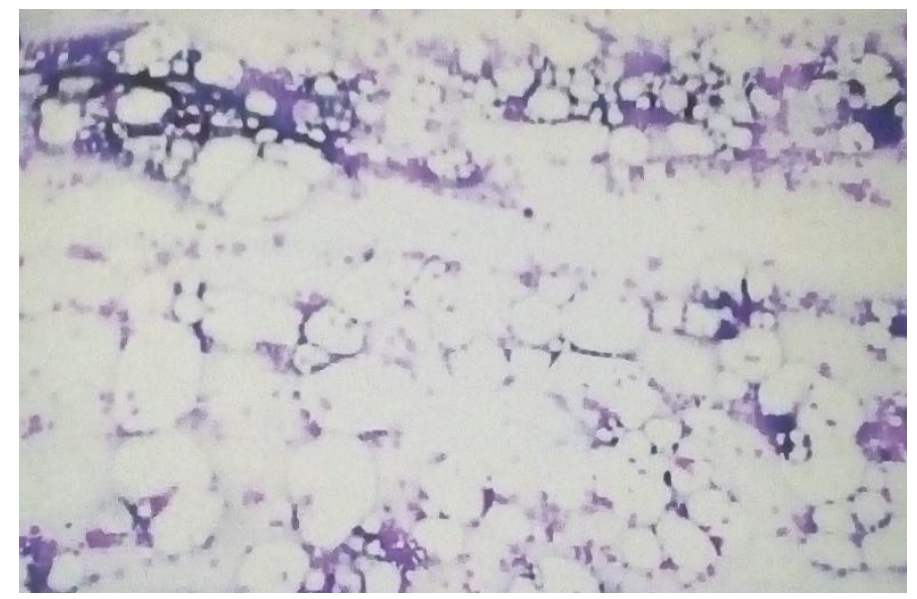

Aplastic anaemia- Bone marrow aspiration smear showing increase in fat cells. (Leishman's stain 40x)

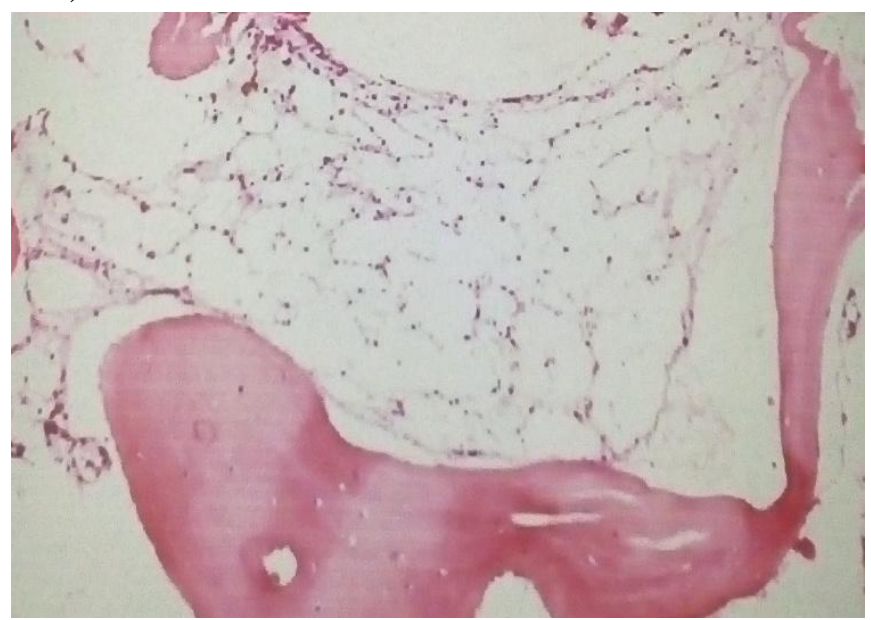




\section{JMSCR Vol||05||Issue||04||Page 20900-20908||April}

Aplastic anemia- Bone marrow trephine biopsy showing increase in fat cells (H\&E stain - 40x)

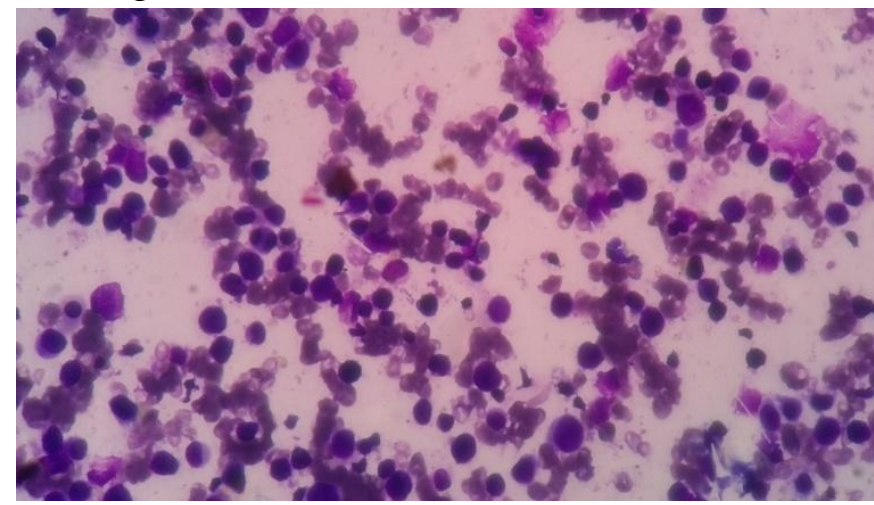

Megaloblastic Anaemia: Aspiration showing megaloblasts having pale blue cytoplasm and nucleus with Sieve-like chromatin (Leishman Stain, 40x)

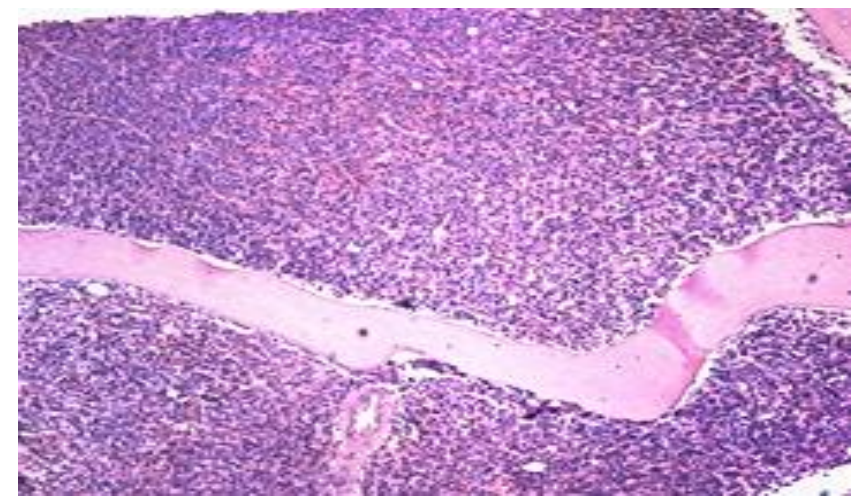

Bone marrow biopsy in low power view 10x showing megaloblast and dyserythropoietic cells (H\&E Stain)

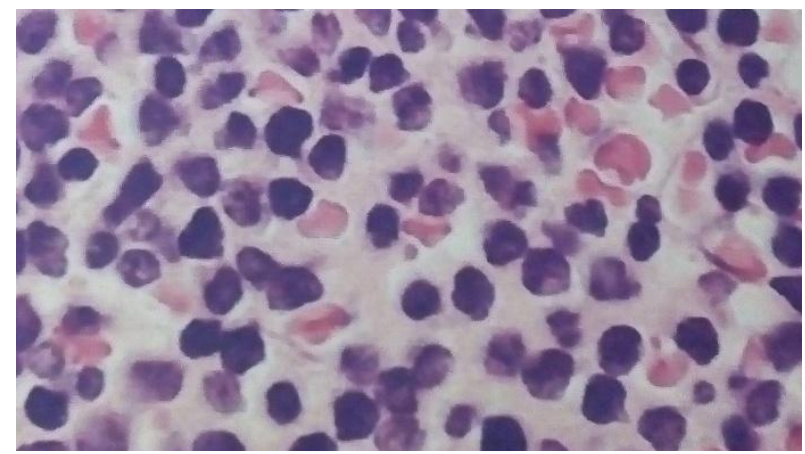

ALL : BMA showing hypercellular marrow having lymphoblasts (Leishman stain-100 x)

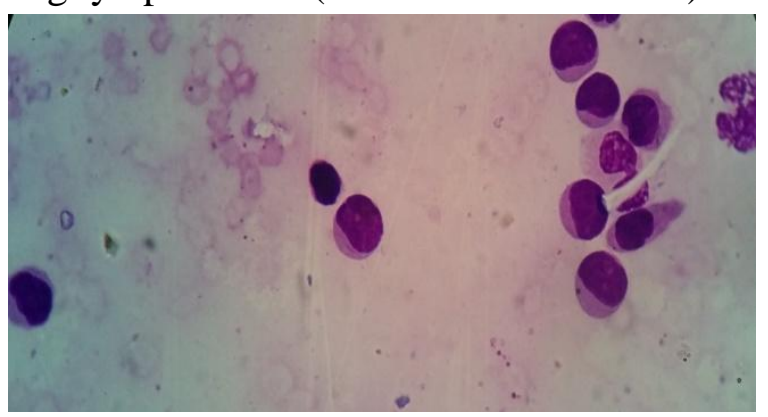

AML:Bone marrow aspiration showing myeloblasts with one myeloblast showing auer rod (Leishman stain, 100x)

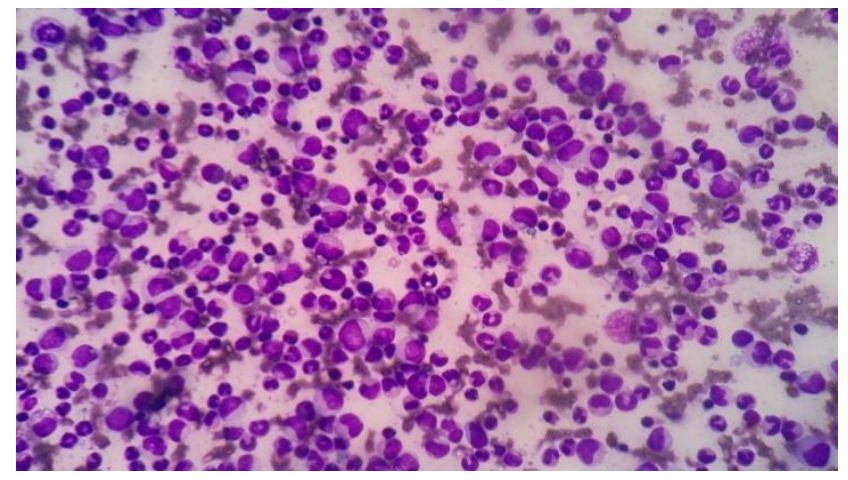

CML: BMA showing myelocytes, metamyelocytes \&neutrophils (Leishman stain, 40x)

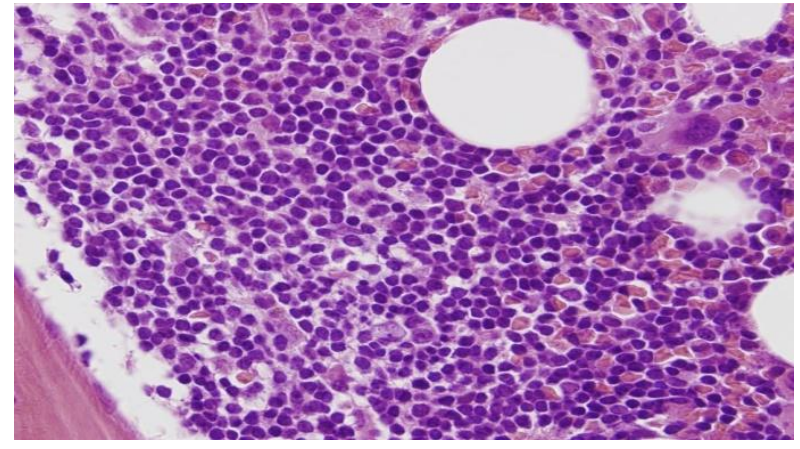

CML: Biopsy showing cells of tightly packed Myelocyte and Metamyelocyte \& neutrophils indifferent stages. ( $\mathrm{H} \& \mathrm{E}, 40 \mathrm{x}$ )

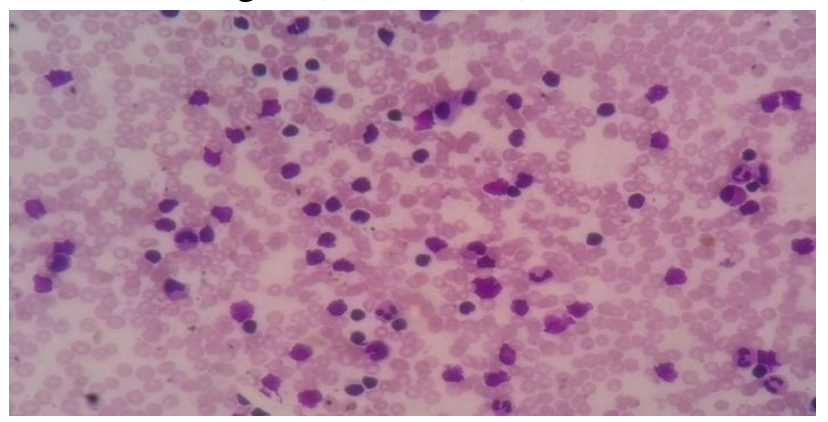

CLL: Bone marrow aspiration showing mature lymphocytes with smudge cells (Leishman stain 40x)

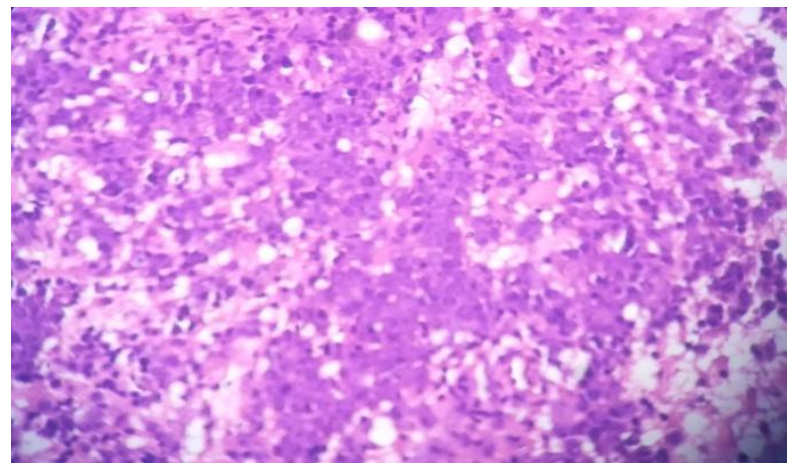


CLL: BMB showing diffuse infiltration of marrow by mature lymphocytes ( $\mathrm{H} \& \mathrm{E}, 40 \mathrm{x}$ )

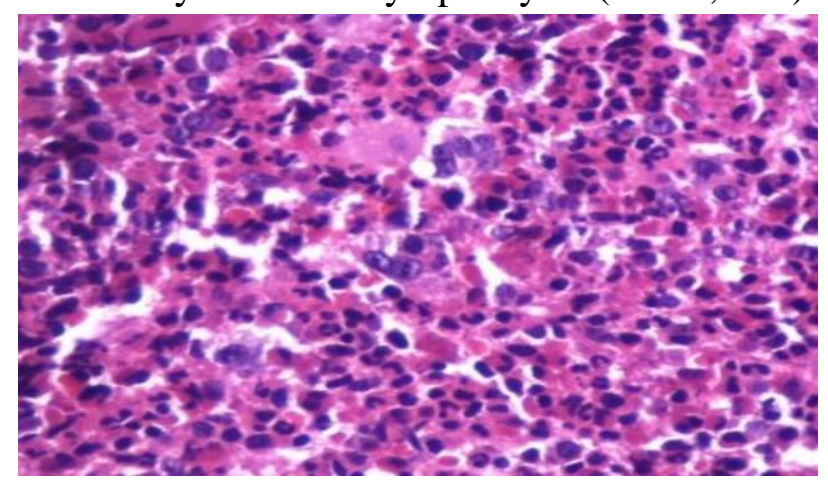

Hodgkin's Lymphoma: Biopsy showing RS like cells (H\&E Stain , 40x)

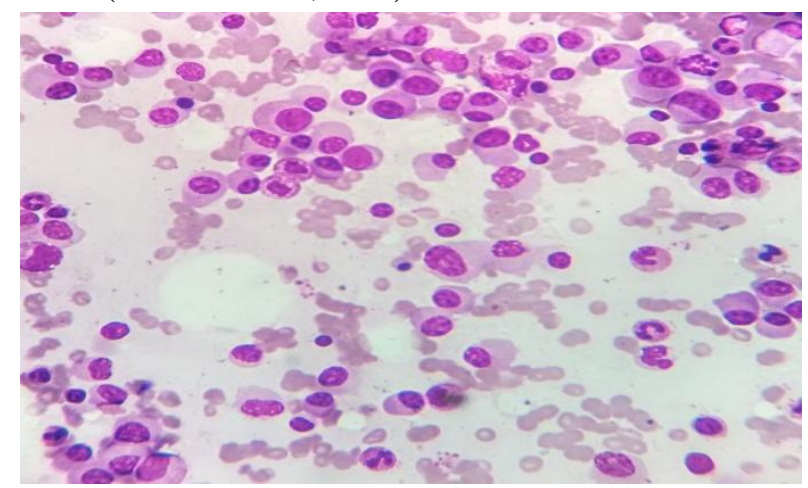

Multiple Myeloma: Aspiration showing plasma cells with eccentric nucleus and perinuclear hof (Leishman Stain, 40x view)

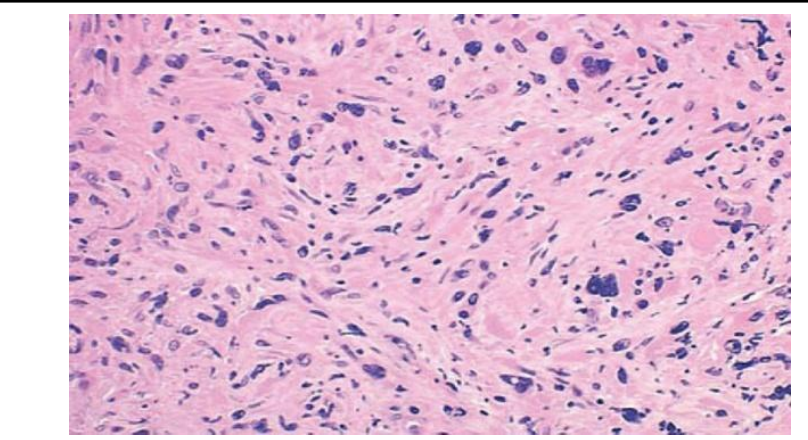

Primary Myelofibrosis: Biopsy showing fibroblasts with few haematopoietic cells $(\mathrm{H} \& \mathrm{E}$, 40x)

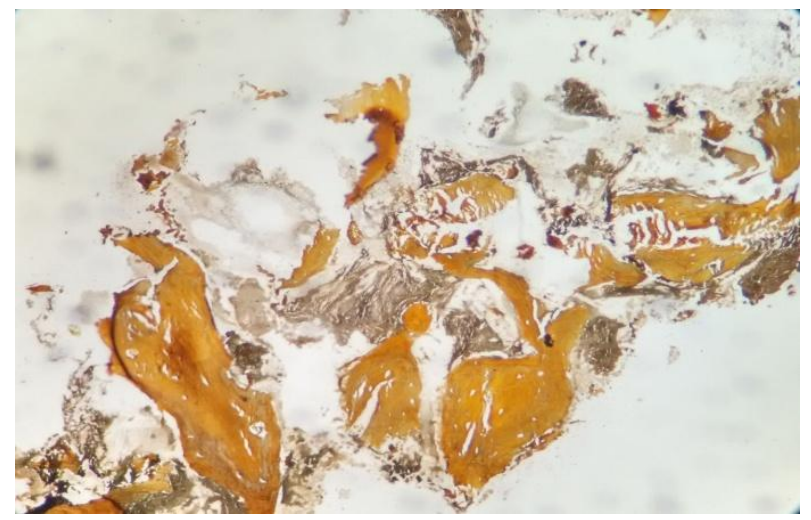

Bone marrow biopsy in Reticulin stain( 10x view) showing fibrosis .

Table 3. - Showing Comparison rate of correlation in different studies.

\begin{tabular}{|l|c|c|c|}
\hline Study & Country & Year & $\begin{array}{c}\text { positive correlation in BMA and } \\
\text { trephine biopsy (\% cases) }\end{array}$ \\
\hline Lukas B et al. $^{(16)}$ & Switzerland & 2005 & 80.5 \\
\hline Toi Pc et al. $^{(22)}$ & India & 2010 & 61.25 \\
\hline Chandra S et al. $^{(20)}$ & India & 2011 & 78 \\
\hline Mahajan V et al. $^{(26)}$ & India & 2013 & 94 \\
\hline Present Study & India & 2016 & 89.33 \\
\hline
\end{tabular}

Table 4. - Showing Comparison of sensitivity of BM Aspiration cytology in various studies.

\begin{tabular}{|c|c|c|c|}
\hline Study & Country & Year & Sensitivity (\%) \\
\hline Lukas B et al. ${ }^{(16)}$ & Switzerland & 2005 & 92 \\
\hline Chandra S et al. ${ }^{(20)}$ & India & 2011 & 77.5 \\
\hline Pandya A et al. ${ }^{(25)}$ & India & 2012 & 77 \\
\hline Present study & India & 2016 & 83 \\
\hline
\end{tabular}

\section{DISCUSSION}

Aspiration and biopsy using standard fixation, embedding and cutting techniques, generally complement to each other. The overall cellularity of samples was comparable in both the preparations. However aspirate particles smear underestimated the cellularity in few of the cases.
This was supported by the findings in the study by Lukas B et al ${ }^{(16)}$

In the present study the commonest haematological disorder was anemia with 32 cases $(21.33 \%)$. Out of which megaloblastic anemia was the commonest anemia diagnosed on bone marrow examination. out of 32cases 23 cases 
were megaloblastic anemia on BMA which shows $100 \%$ accuracy when compared with BMB (23/23). out of 4 cases of hypoplastic anemia in which 3 cases shows positive findings on BMA while one case show inadequate information due to marrow diluted with peripheral blood. out of 2 cases of aplastic anemia BMA shows dry tap in both the cases in which BMB provide adequate information about the aplastic anemia. One case of dimorphic anemia show positivity on BMA when compared to $\mathrm{BMB}(1 / 1)$ another one case on BMA shows microcytic hypochromic anemia and BMB shows erythroid hyperplasia on examination. Overall of above findings megaloblastic anemia was the commonest anemia and cases were $15.33 \%$. Which are closely related to study by Mahajan $\mathrm{v}$ et $\mathrm{al}^{(26)}$ in which megaloblastic anemia cases were $18.47 \%$.

An important limitation of bone marrow examination obtained by aspirate is the admixing of marrow and sinusoidal blood, which may not allow for reliable estimates of marrow cellularity. This evaluation is of particular importance in the hypercellular marrow which yields a "dry tap" or only dilutes sinusoidal blood. Thus the use of biopsy avoids misinterpretation of cellularity by smear in patients whom the biopsy confirmed a normal, hypocellular or hypercellular marrow. Percentage of 'dry taps' was $2.66 \%$ all of which diagnosed on bone marrow biopsy sections. Total four cases were put in dry tap category out of which two cases were aplastic anemia, which were 28 and 18 years male patient. Bone marrow aspiration was 'dry tap' while trephine biopsy showed reduced cellularity, with fat cells occupying more than $75 \%$ of the marrow in both cases. There were scattered nests of erythropoietic cells with relative increase in the number of lymphocytes and few plasma cells.

one case was primary myelofibrosis which shows dry tap on BMA due to fibrosis of bone marrow .This patient was 45 years old male and splenomegaly was the only physical finding at presentation, our findings were comparable to study by Silverstein et al. ${ }^{(1)}$
Another single case was secondary myelofibrosis which also shows dry tap on BMA and BMB provide positive information about this case. It is necessary that findings of a dry tap should never be dismissed as benign due to faulty technique and always need a bone marrow biopsy. ${ }^{(2,17,25)}$

In the present study, out of 150 cases, 28 $(18.66 \%)$ cases were evaluated for pancytopenia, which was in close agreement with study by Jha et al. ${ }^{(24)}$ The frequency of bone marrow examination for evaluation of pancytopenia was $17.34 \%$

In our study patients of acute leukemia were 19 (12.67\%) in which 3cases(15.78\%) were ALL and all 3 patient were male. Patient of AML were $16(84.22 \%)$, male to female ratio was $4: 1$ and maximum patients were in third to fourth decade of life. For all the 3 cases of ALL both the methods revealed concordant results and BMA shows $100 \%$ accuracy when compared to bone marrow trephine biopsy. For AML out of 16 cases 15 cases on BMA provide positive information which shows $93.75 \%$ accuracy on BMA. One case was provide inadequate information on BMA due to marrow diluted with peripheral blood, in this case $\mathrm{BMB}$ provide positive diagnosis. The assessment of overall cellularity, residual hematopoietic tissue and myelofibrosis which all affect the prognosis and treatment of patient can be known only by examination of trephine biopsy section. $^{(15)}$

Out of 150 cases, CML cases were 16 (10.66\%) in which 14 cases shows positive correlation on BMA, the percent value on BMA was $87.5 \%$, cases were between third decade to seventh decade of life. In two cases BMA was diluted due to peripheral blood so could not provide adequate information in these cases bone marrow trephine biopsy gave positive findings. In our study eleven cases of CLL, 8 were male and 3 were female patient, $\mathrm{M}: \mathrm{F}$ ratio was $2.6: 1$. This was comparable to study of Rozman et al. ${ }^{(8)}$ who studied 329 patients, $208(63.22 \%)$ cases were male and 121 (36.78\%) female. In our study out of eleven cases 9 cases gave positive information on BMA (9/11) which shows $81.81 \%$ accuracy on BMA, 
remaining two cases could not provide diagnostic clue due to BMA diluted with peripheral blood, these cases required $\mathrm{BMB}$ for adequate information. Almost all the cases have diffuse involvement of marrow which can be seen on biopsy sections, while aspiration only shows that marrow is involved. Pattern of marrow involvement by leukemic cells could be analysed by trephine biopsy.

There were $3(2 \%)$ cases of NHL all were male patient, which were diagnosed on bone marrow biopsy, out of which 2 cases $(66.66 \%)$ provide positive clue on bone marrow aspiration, remaining one case could not provide adequate cellularity on BMA due to diluted with peripheral blood. This is in favour with the results of Musolino et al. ${ }^{(21)}$ where $9.8 \%$ cases were positive on only aspiration. However both aspiration and biopsy should be done in case of suspected NHL to reaching at definite diagnosis.

In our study there were 3 cases of Hodgkin's lymphoma diagnosed on BMB. Male to female ratio was 1:2 out of which two patient were within first two decade of life another one female patient was 55year old. Out of 3cases two cases gave positive information on $\operatorname{BMA}(66.66 \%)$ while one case could not provide information due to inadequate cellularity, BMA diluted with peripheral blood in this case.

There were $6(4 \%)$ cases were diagnosed as multiple myeloma. Male to female ratio was 1:1. All the patients presented with bone pain and osteolytic punched out lesions were suggestive on radiograph. Singhal et al ${ }^{(14) .}$ reported $30(61.22 \%)$ males and $19(38.77 \%)$ females, out of 49 patients. The median age was 57 years. The most common symptom was bone pain in $22(45 \%)$ cases, pathological fractures in $17(34.7 \%)$ cases similar to Bartl R et al. ${ }^{(6)}$

In our study out of 6 cases of multiple myeloma, in one case bone marrow aspirate smear shows inadequate information for accurate diagnosis, while 5cases show positive information on BMA. Thus BMA accuracy was $83.33 \%$. In one case the bone marrow biopsy section provided the diagnosis in this case. Similar results were obtained by Sabharwal et al. ${ }^{(7)}$

In our study there were five cases of non hematological disorders. There were two cases of metastatic lesion and three cases were granulomatous lesion. In two case of metastatic lesion.out of which one case was a 7 year male child who was diagnosed as neuroblastoma. On bone marrow biopsy examination two small cluster of metastatic lesion found. In this case BMA could not provide adequate information due to inadequate cellularity. Another case was a 43year female patient in which BMA shows positive clue for metastatic cells and bone marrow biopsy shows involvement by metastatic lesion provide definite diagnosis of this case. In three cases of granulomatous lesion, all three cases diagnosed on BMB while two cases shows normal study on BMA due to patchy involvement of bone marrow, remaining one case could not provide adequate information due to inadequate cellularity of BMA. These findings are indicate necessity of BMB examination. ${ }^{(16,20,22,26)}$

\section{CONCLUSION}

In conclusion, this study yielded some important information suggested that aspiration is easy to perform and important for cytological assessment with analysis directed towards morphology and obtaining a differential count while bone marrow trephine biopsy is slightly more painful and requires more skill performance and more reliable in assessing cellularity, bone marrow architectural pattern, distribution and fibrosis, bone marrow biopsy is diagnostic investigation in 'dry tap' aspiration cases, which occur when the marrow is fibrotic or densely cellular. Overall both the procedures are complementary to each other and must be performed together for better evaluation of bone marrow.

\section{REFERENCES}

1. Silverstein MN. Agnogenic myeloid metaplasia. Publishing Sciences group action 1975. 
2. Navone R, Colombano MTHisopathological trephine biopsy findings in cases of 'Dry-Tap' bone marrow aspiration. Appl. Pathol 1984; 2: 264-271.

3. Tricot G, Wolf-Peeter CDE, Vliethinck R, Verwilghen RL. Bone marrow histology in myelodysplastic syndrome and comparison with bone marrow smears. Br. J Hematol 1984a; 57: 423-430.

4. Tricot G, Vlietinck R, Boogaerts MA. Prognostic factors in myelodysplastic syndromes: importance of initial data on peripheral blood counts, bone marrow cytology, trephine biopsy and chromosomal analysis. Br. J Haematol 1985, 60: 19-32.

5. Pasquale D, Chikkapa G comparative evaluation of bone marrow aspirate particle smears, biopsy imprints and biopsy sections. Am J Hematol(1986) 22:381-389.

6. Bartl R, Frisch B, Moghadam A, Kelther G, Jaeger K, Sommerfeld W. Histologic classification and staging of multiple myeloma- A retrospective study of 674 cases. Am J ClinPathol 1987; 87:342-355.

7. Sabharwal BD, Malhotra V, Aruna S, Grewal R. Comparative evaluation of bone marrow aspirate particle smears, imprints and biopsy sections. J Postgrad Med 1990; 36(4) : 194-8.

8. Rozman C, Montserrat E. Chronic lymphocytic leukemia. N. Engl J Med 1995;333:1052-1057.

9. Barekman CL, Fair KP, Cotelingam JD Comparative utility of diagnostic bone marrow components: a 10 year study. Am J Hematol(1997).56:37-41.

10. Bain BJ Bone marrow aspiration. J clinPathol 2001; 54: 657-663.

11. Bain BJ bone marrow trephine biopsy. J ClinPathol 2001; 54: 742-757.

12. Khodke K, Marwah S, Buxi G, Yadav RB, Chaturvedi NK. Bone marrow examination is cases of pancytopenia. JIACM 2001;1:55-59.
13. Nanda A, Basu S, Marwaha N, bone marrow trephine biopsy as an adjunct to bone marrow aspiration. J Assoc. Physicians India 2002; 50: 893-895.

14. Singhal N, Singh T, Singh ZN, Shome DK, Gaiha M. Histomorphology of multiple myeloma on bone marrow biopsy. Indian J Pathol Microbiol 2004.; 47(3): 359-363

15. Sitalakshmi S, Anuradhas, Betty Alexander. The diagnostic utility of bone marrow trephine biopsies. Indian J Pathol microbiol 2005; 48(2) : 173-176.

16. Lukas B, Korte W, Schmid L, Cogliatti SB. Impact of aspirate smears and trephine biopsies in routine bone marrow diagnostics : a comparative study of 141 cases. Swiss Med WKLY 2005;135: 151159.

17. Humphries JE. Dry tap bone marrow aspirate: clinical significance. Am J Hematology 2006;35: 247-50.

18. Makaju S. Incidence of aplastic anaemia, the relevance of diagnostic criteria. Blood 2009;70;1718-21.

19. Greer JP, Foester J, Rodgers GM, Paraskevas F, Glador B. wintrobe's clinical Hematology $12^{\text {th }}$ Ed. Lippincott Williams and Wilkins; 2009.

20. Chandra S, Chandra H, Saini S, Bone marrow metastasis by solid tumors. Probable heamatopoietic indicators and Comparision of bone marrow aspirate, touch imprint and trephine biopsy. Haematology 2010; 15: 368-72.

21. Musolino A, Guazzi A, Nizzoli R, Mancini. Accuracy and relative value of bone marrow aspiration in the detection of lymphoid infiltration in non-Hodgkin's lymphoma. Tumori 2010;96: 24-27.

22. Toi PC, Varghese RG,Rai R. Comparative evaluation of simultaneous Bone marrow aspiration and bone marrow biopsy: An institutional experience. Indian $\mathrm{J}$ Hemato Blood Transfus. 2010; 26(2): 41-4. 
23. Chandra S, Chandra H. Comparison of bone marrow aspirate cytology, touch imprint cytology and trephine biopsy for bone marrow evaluation. Hematol Rep 2011; 3:65-68.

24. Pathak R, Jha R, Sayami G. Evaluation of bone marrow in patients with pancytopemia. JNMA J Nepal Med. Assoc. 2012; 2: 265-271.

25. Pandya A, Patel T, Shah N. Comparative utility of bone marrow aspiration and bone marrow biopsy. J Med 2012; 1:987-993.

26. Mahajan V, Kaushal V, Thakur S, Kaushik R. A comparative study of bone marrow aspiration and biopsy in haematological disorders - an institutional experience. JIACM 2013: 14(2): 133-5. 